\title{
Removal of Methylene Blue from Aqueous Solutions Using Fly Ash Modified with Sodium Hydroxide
}

\author{
EBELEGI NEWTON AUGUSTUS, AYAWEI NIMIBOFA* and WANKASI DONBEBE
}

Department of Chemical Sciences, Niger Delta University, Wilberforce Island, Bayelsa State, Nigeria

ayawei4acad@gmail.com

Received 17 February 2016 / Accepted 20 March 2016

\begin{abstract}
Fly ash was modified by chemical treatment with $\mathrm{NaOH}$ solutions of varying concentrations (4, 3, 2 and $1 \mathrm{M})$ and labeled SHFA-4, SHFA-3, SHFA-2, SHFA-1 respectively. All four forms of fly ash were tested as adsorbents for the removal of methylene Blue dye from aqueous solutions. The effect of contact time and concentration were investigated using a batch adsorption technique. The experimental data could best be described by the Freundlich isotherm and the dynamic data fit well with the pseudo-second-order kinetic model, which suggests that the adsorptions appeared to be multilayer adsorption processes. Fly ash modified with $4 \mathrm{M} \mathrm{NaOH}$ (SHFA-4) demonstrated the highest adsorption capacity $\left(\mathrm{K}_{\mathrm{F}}=77.04 \mathrm{mg} / \mathrm{L}\right)$. The kinetic data confirms the applicability of the pseudosecond-order kinetic model which indicates multilayer adsorption processes. These results suggests that fly modified with $\mathrm{NaOH}$ could be employed as a low cost adsorbent for the removal of methylene blue form wastewater streams from textile, tanning and printing industries.
\end{abstract}

Keywords: Adsorption, Methylene Blue, Freundlich Isotherm, Fly ash

\section{Introduction}

As globalization continues and the earth's natural processes transform local problems into international issues, a few societies are left untouched by major environmental problems ${ }^{1}$. The textile industry ranks high among polluting industries because it uses large quantities of water during the dyeing process and as such the discharged effluents are loaded with pollutants such as dyes ${ }^{2}$. The discharge of colored wastewater from paper and pulp, textile and dyeing, leather, printing and food industries is becoming a serious environmental concern because many azo dyes and their intermediates have toxic effects on environment and human health due to their carcinogenicity and visibility ${ }^{3,4}$.

Adsorption can perform many separations that are impractical by conventional techniques such as distillation, absorption and even membrane based systems ${ }^{5}$. Adsorption techniques are applied because of advantages such as low cost, ease of operation, efficiency, simplicity of equipment and most importantly the adsorbent can be sourced from a wide range of materials such as, fly $a^{6} h^{6}$. 
Fly ash is one of the most known industrial waste and it is been used as pozzolanic material to enhance physical, chemical and mechanical properties of cements and concretes ${ }^{7}$, but it's negative impact on the environment and cannot be completely neutralized by doing this, so reusing it as an adsorbent in the removal of methylene blue from aqueous solution is a step in the right direction ${ }^{8,9}$.

\section{Experimental}

The pulverized coal was obtained from a factory in South Africa. The adsorbents were prepared using a modification of the procedure literature ${ }^{10} .40 .0 \mathrm{~g}$ of $\mathrm{NaOH}$ crystals was dissolved in $250 \mathrm{~mL}$ of distilled water (4 M NaOH solution), serial dilutions with distilled water was carried out to prepare $3 \mathrm{M}, 2 \mathrm{M}$ and $1 \mathrm{M} \mathrm{NaOH}$ solutions respectively. $10.0 \mathrm{~g}$ of unmodified fly ash was weighed into a $250 \mathrm{~mL}$ conical flask. $100 \mathrm{~mL}$ of varied concentrations of $\mathrm{NaOH}$ (from $1 \mathrm{M}$ to $4 \mathrm{M}$ ) was added the conical flask containing unmodified fly ash and covered with a stopper. The slurries were stirred on a magnetic stirrer for 24 hours. The sample was filtered and the solid extract was dried in an oven and crushed into a fine powder.

\section{Preparation of adsorbate solution}

$0.3 \mathrm{~g}$ of Analytical grade methylene blue powder was dissolved in $1000 \mathrm{~mL}$ of distilled water $(3000 \mathrm{mg} / \mathrm{L})$, this served as the stock solution for serial dilutions into $25 \mathrm{mg} / \mathrm{L}$, $50 \mathrm{mg} / \mathrm{L}$ and $100 \mathrm{mg} / \mathrm{L}$ respectively.

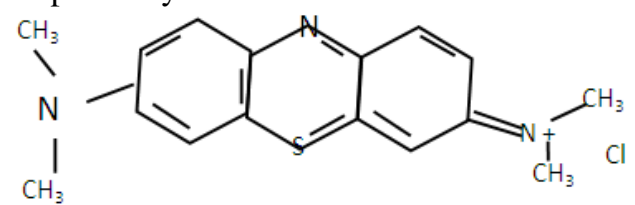

Figure 1. Chemical Structure of Methylene blue

\section{Characterization of fly ash}

Energy dispersive spectroscopy was applied to study the elemental components of fly ash.

\section{Adsorption studies}

Equilibrium and kinetic adsorption experiments were conducted in batches at room temperature with a Stewart Reciprocating Shaker at 100 rotations per minute.

The contact time was evaluated on samples of $0.2 \mathrm{~g}$ of fly ash modified with various concentrations of $\mathrm{NaOH}$ (i.e. fly ash modified with $4 \mathrm{M} \mathrm{NaOH}$, fly ash modified with $3 \mathrm{M}$ $\mathrm{NaOH}$, fly ash modified with $2 \mathrm{M} \mathrm{NaOH}$ and fly ash modified with $1 \mathrm{NaOH}$ ) in $10 \mathrm{~mL}$ of dye solution, each sample was tested with $25 \mathrm{mg} / \mathrm{L}, 50 \mathrm{mg} / \mathrm{L}$ and $100 \mathrm{~m} / \mathrm{L}$ of congo red solution for 60 minutes.

$100 \mathrm{mg} / \mathrm{L}$ of Congo red was tested on all modified forms of fly ash for 10, 30, 60 and 90 minutes respectively. The substrates were separated from supernatant with use of a centrifuging machine, operated for 10 minutes at 30 revolutions per minute. Equilibrium concentrations of the supernatant were analyzed with Jenway 6,300 spectrophotometer at $\lambda_{\max }=665 \mathrm{~nm}$ after calibration.

\section{Adsorption isotherms}

Congo red adsorption on fly ash modified with $\mathrm{NaOH}$ was analyzed using Langmuir type II, Freundlich and Florry-Huggins isotherms. 
The Langmuir Isotherm was used to characterize the monolayer adsorption, which is represented by the equation;

$$
\frac{1}{q_{e}}=\frac{1}{b}+\frac{1}{a b c_{e}}
$$

Where $\mathrm{q}_{\mathrm{e}}=$ amount of dye adsorbed at equilibrium $(\mathrm{mg} / \mathrm{L})$,

$\mathrm{C}_{\mathrm{e}}=$ equilibium concentration of dye $(\mathrm{mg} / \mathrm{L})$, a and $\mathrm{b}$ are Langmuir constants

The Freundlich Isotherm is generally applicable to adsorption that occurs on heterogeneous surfaces. The linear form is shown below:

$$
\ln q_{e}=\ln k_{f}+\frac{1}{n} \ln c_{e}
$$

Where, $k_{f}$ and $n$ are Freundlich constants related to adsorption capacity and adsorption intensity, respectively. The Florry-Huggins isotherm considers the surface behavior of the adsorbates and adsorbents, the surface covered by the adsorbate can be calculated from the equation;

$$
\log \frac{\theta}{c_{e}}=\log k_{a}+n \log (1-\theta)
$$

Where $\mathrm{k}_{\mathrm{a}}=$ equilibrium constant of adsorption, $n=$ number of adsorbates occupying adsorbent site, and $\theta=$ degree of surface coverage.

\section{Adsorption kinetics}

In order to investigate the mechanism of adsorption, kinetic models such as the zero-order, first order, second-order, pseudo-second order and third-order kinetic models were applied to study the adsorption dynamics.

$$
\begin{aligned}
& \text { Zero-order kinetic model } \mathrm{q}_{\mathrm{t}}=\mathrm{q}_{\mathrm{o}}+\mathrm{k}_{\mathrm{o}} \mathrm{t} \\
& \text { First-order kinetic model } \operatorname{lng}_{\mathrm{t}}=\ln \mathrm{q}_{\mathrm{o}}+\mathrm{k}_{1} \mathrm{t} \\
& \text { Second-order kinetic model } 1 / \mathrm{q}_{\mathrm{t}}=1 / \mathrm{q}_{\mathrm{o}}+\mathrm{k}_{2} \mathrm{t} \\
& \text { Pseudo-second-order kinetic model } \frac{t}{q_{t}}=\frac{1}{h_{o}}+\left(\frac{1}{q_{t}}\right) t \\
& \text { Third-order kinetic model } \frac{1}{q_{t}^{2}}=\frac{1}{q_{0}^{2}}+k_{3} t
\end{aligned}
$$

\section{Results and Discussion}

\section{EDS}

The elemental analysis (Figure 2) indicated that the fly ash used or this study had the following composition; Carbon (43.4\%), Oxygen (33.4\%), Silicon (9.3\%), Aluminum $(8.1 \%)$, Calcium $(4.8 \%)$, Iron $(0.2 \%)$, Potassium $(0.2 \%)$, Magnesium $(0.2 \%)$, and Sulphur $(0.2 \%)$. 


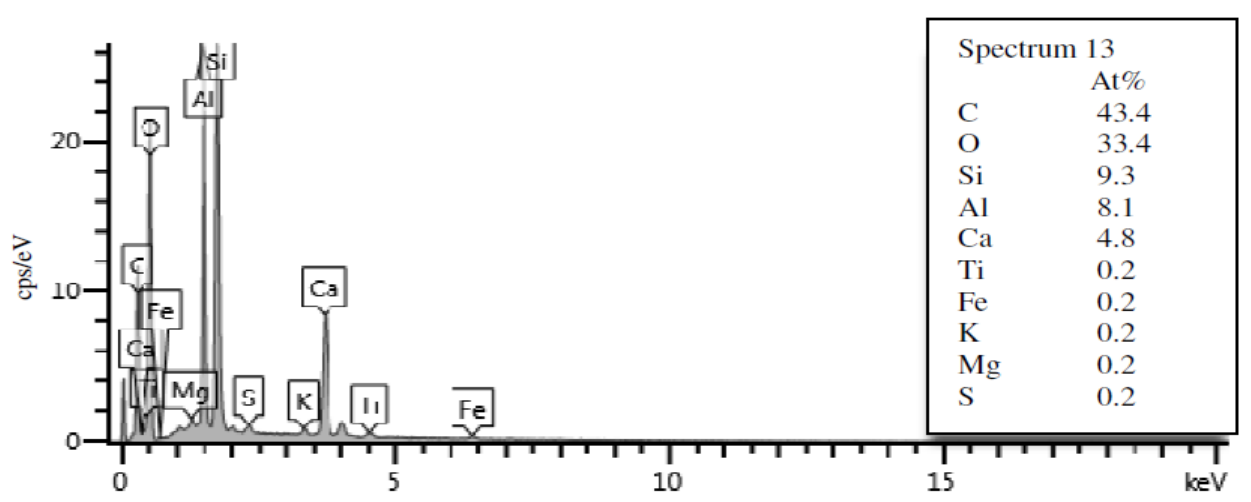

Figure 3. EDS Spectrum of fly ash

\section{Effect of initial concentration}

In order to study the effect of different concentrations of dyes on adsorption behavior three concentrations $(25,50$ and $100 \mathrm{mg} / \mathrm{L})$ were used and the amounts adsorbed were obtained as shown in Table 1.

Table 1 shows that the amount of dye adsorbed increased from $23.4 \mathrm{mg} / \mathrm{L}$ to $92.2 \mathrm{mg} / \mathrm{g}$ for fly ash modified with $4 \mathrm{M} \mathrm{NaOH}, 23.2 \mathrm{mg} / \mathrm{L}$ to $98.6 \mathrm{mg} / \mathrm{g}$ for fly ash modified with $3 \mathrm{M}$ $\mathrm{NaOH}, 24.3 \mathrm{mg} / \mathrm{L}$ to $98.0 \mathrm{mg} / \mathrm{g}$ for fly ash modified with $2 \mathrm{M} \mathrm{NaOH}$ and $24.1 \mathrm{mg} / \mathrm{L}$ to $98.7 \mathrm{mg} / \mathrm{g}$ for fly ash modified with $1 \mathrm{M} \mathrm{NaOH}$. The observed increase in the adsorption of methylene blue with increase in initial concentration may be ascribed to sufficient adsorption sites at the adsorbent ${ }^{11}$.

Table 1. Amount (mg/g) and percentage of dye adsorbed

\begin{tabular}{|c|c|c|c|c|c|c|c|c|}
\hline \multirow{2}{*}{$\begin{array}{c}\text { Initial } \\
\text { concentration } \\
\text { of methylene } \\
\text { blue }\end{array}$} & \multicolumn{2}{|c|}{$\begin{array}{c}\text { Fly ash modified } \\
\text { with } 4 \mathrm{M} \mathrm{NaOH} \\
\text { (SHFA-4) }\end{array}$} & \multicolumn{2}{|c|}{$\begin{array}{c}\text { Fly ash modified } \\
\text { with } 3 \mathrm{M} \mathrm{NaOH} \\
(\mathrm{SHFA}-3)\end{array}$} & \multicolumn{2}{|c|}{$\begin{array}{c}\text { Fly ash modified } \\
\text { with } 2 \mathrm{M} \mathrm{NaOH} \\
\text { (SHFA-2) }\end{array}$} & \multicolumn{2}{|c|}{$\begin{array}{c}\text { Fly ash modified } \\
\text { with } 1 \mathrm{M} \mathrm{NaOH} \\
\text { (SHFA-1) }\end{array}$} \\
\hline & $\mathrm{mg} / \mathrm{g}$ & $\%$ & $\mathrm{mg} / \mathrm{g}$ & $\%$ & $\mathrm{mg} / \mathrm{g}$ & $\%$ & $\mathrm{mg} / \mathrm{g}$ & $\%$ \\
\hline $25 \mathrm{mg} / \mathrm{L}$ & 23.4 & 93.6 & 23.2 & 92.8 & 24.2 & 96.8 & 24.1 & 96.4 \\
\hline $50 \mathrm{mg} / \mathrm{L}$ & 47.7 & 95.4 & 47.5 & 95.0 & 48.8 & 97.6 & 48.9 & 97.8 \\
\hline $100 \mathrm{mg} / \mathrm{L}$ & 92.2 & 92.4 & 98.6 & 96.8 & 98.0 & 98.8 & 98.7 & 98.7 \\
\hline
\end{tabular}

\section{Adsorption isotherms}

The adsorption isotherms were studied using initial concentrations of $25 \mathrm{mg} / \mathrm{L}, 50 \mathrm{mg} / \mathrm{L}$ and $100 \mathrm{mg} / \mathrm{L}$ at an adsorbent dosage of $0.2 \mathrm{~g} / \mathrm{L}$. Three adsorption isotherms (Langmuir, Freundlich and Florry-Huggins) were adopted to investigate methylene blue behavior on SHFA-4, SHFA-3, SHFA-2 and SHFA-1. The parameters of the three adsorption isotherms are listed in Table 2.

Although Langmuir isotherm gives high correlation coefficients $\left(\mathrm{R}^{2}\right)$ however, the sorption factor $\left(\mathrm{S}_{\mathrm{F}}\right)$ for SHFA-4 (-0.317), SHFA-3 (-0.23), SHFA-2 (-0.163) and SHFA-1 $(-0.063)$ are all less than zero which is a clear indication that this isotherm type is unfavorable $^{12}$. Freundlich isotherm fit the experimental data due to high correlation coefficients $\left(\mathrm{R}^{2}\right)$ as shown in Figures 3-6 and this may be attributed to the heterogeneous distribution of active sites and multilayer adsorption of methylene blue on fly ash modified with $\mathrm{NaOH}^{8}$. The adsorption capacity $\mathrm{K}_{\mathrm{F}}$ of SHFA-1 (77.04) obtained from Freundlich isotherms is larger than $\mathrm{K}_{\mathrm{F}}$ of SHFA-2 $\left(\mathrm{K}_{\mathrm{F}} 75.02\right)$, SHFA-4(56.44) and SHFA-3 $\left(\mathrm{K}_{\mathrm{F}}=26.04\right)$ 
indicating that SHFA-1 more affinity for methylene blue than SHFA-2, SHFA-4 and SHFA-3. The numerical values of $1 / \mathrm{n}$, obtained from the Freundlich plot were greater than one (1) for all modified forms of fly ash SHFA-4 (1.637), SHFA-3 (2.486), SHFA-2 (1.521), SHFA-1 (3.851) which indicates that sorption capacity was exceeded at higher concentrations and this predicts saturation of the sorbent by the sorbate and this indicates multilayer adsorption and finite surface coverage by the adsorbate on the adsorbent ${ }^{13}$.

Table 2. Parameters of three adsorption isotherms for methylene blue adsorption on modified fly ash samples

\begin{tabular}{cccccc}
\hline Isotherm model & Parameter & SHFA-4 & SHFA-3 & SHFA-2 & SHFA-1 \\
\hline Langmuir & $\mathrm{S}_{\mathrm{F}}$ & -0.317 & -0.23 & -0.163 & -0.063 \\
& $\mathrm{R}^{2}$ & 0.966 & 0.985 & 0.983 & 0.992 \\
Freundlich & $\mathrm{K}_{\mathrm{F}}(\mathrm{mg} / \mathrm{L})$ & 56.55 & 26.04 & 75.02 & 77.04 \\
& $1 / \mathrm{n}$ & 1.637 & 2.486 & 1.521 & 3.851 \\
& $\mathrm{R}^{2}$ & 0.991 & 0.993 & 0.995 & 0.997 \\
Florry-Huggins & $\mathrm{K}_{\mathrm{a}}$ & 0.607 & 0.6462 & 1.8001 & 0.333 \\
& $\mathrm{R}^{2}$ & 0.548 & 0.982 & 0.983 & 0.999 \\
\hline
\end{tabular}

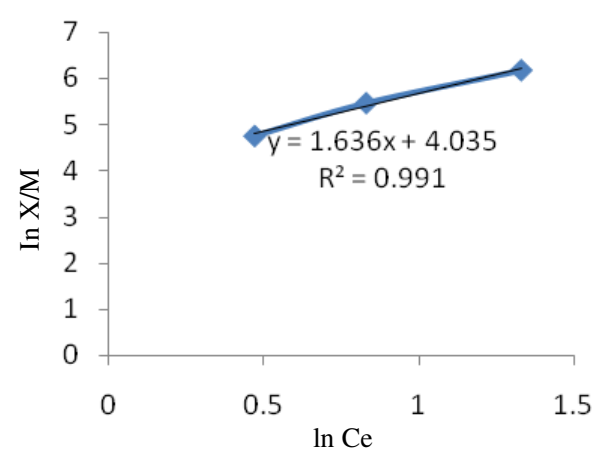

Figure 3. Freundlich plot for the sorption of MB on SHFA-4

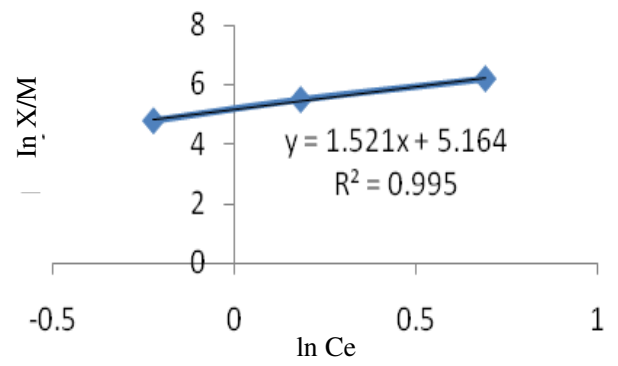

Figure 5. Freundlich plot for the sorption of MB on SHFA-2

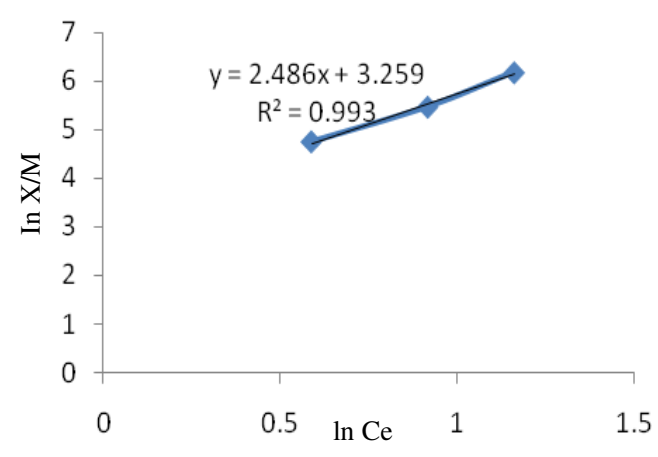

Figure 4. Freundlich plot for the sorption of MB on SHFA-3

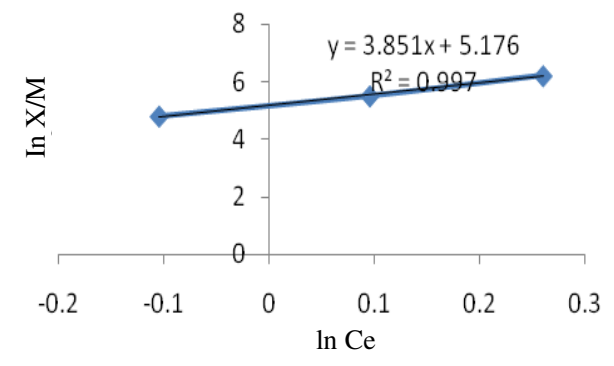

Figure 6. Freundlich plot for the sorption of on SHFA-1

\section{Adsorption kinetics}

Adsorption kinetics is an effective method to evaluate the mechanism of methylene blue adsorption on modified forms of fly ash ${ }^{14,15}$. Five adsorption kinetics models ( zero-order model, 
first-order model, second-order model, pseudo-second-order model and third-other model) were applied to examine the experimental data. Table 3 reveal that the adsorption data of SHFA-4,SHFA-3,SHFA-2 and SHFA-1 fit the pseudo-second-order model accurately due to the high correlation coefficients $\left(\mathrm{R}^{2}\right)$, which suggests that methylene blue adsorption onto fly ash modified with sodium hydroxide appeared to be a multilayer sorption process, with non uniform distribution of adsorption affinities over heterogeneous surfaces ${ }^{16,17}$.

Table 3. Correlation coefficients for kinetic models the adsorption of methylene blue onto fly ash modified with $\mathrm{NaOH}$

\begin{tabular}{llllc}
\hline \multicolumn{1}{c}{ Kinetic model } & $\begin{array}{c}\text { SHFA-4 } \\
\mathrm{R}^{2}\end{array}$ & $\begin{array}{c}\text { SHFA-3 } \\
\mathrm{R}^{2}\end{array}$ & $\begin{array}{c}\text { SHFA-2 } \\
\mathrm{R}^{2}\end{array}$ & $\begin{array}{c}\text { SHFA-1 } \\
\mathrm{R}^{2}\end{array}$ \\
\hline Zero-order & 0.0967 & 0.8466 & 0.0068 & 0.5102 \\
First-order & 0.0933 & 0.8623 & 0.008 & 0.5102 \\
Second-order & 0.1045 & 0.8466 & 0.0544 & 0.5102 \\
Pseudo-second-order & 1 & 1 & 1 & 1 \\
Third-order & 0.0763 & 0.8611 & 0.0068 & 0.5102 \\
\hline
\end{tabular}

Gibbs free energy of sorption $\left(\Delta G_{a d s}^{o}\right)$

The Gibbs free energy of sorption $\Delta G_{a d s}^{o}$ is a fundamental means of measuring spontaneity consequently, adsorption occurs spontaneously at a given temperature if the Gibbs free energy of adsorption is negative ${ }^{18,19}$. The Gibbs free energy of sorption of methylene blue by SHFA-4, SHFA-3, SHFA-2 and SHFA-1 were evaluated at room temperature (303 K) using the following equation, the resultant values are shown in Table 4.

$$
\Delta G_{a d s}^{o}=-R T \ln K_{a}
$$

Where $\mathrm{R}=$ Universal gas constant $\left(8.314 \mathrm{JK}^{-1} \mathrm{~mol}^{-1}\right)$

$\mathrm{T}=$ Absolute temperature $(303 \mathrm{~K})$

$\mathrm{K}_{\mathrm{a}}=$ Equilibrium constant of sorption obtained from Florry-Huggins plot

The Gibbs free energy of adsorption values shown in Table 4 reveal that only the adsorption of methylene blue onto SHFA-2 was spontaneous.

Table 4. Gibbs free energy of sorption of Methylene blue by SHFA-4, SHFA-3, SHFA-2 and SHFA-1

\section{Conclusion}

\begin{tabular}{ccc}
\hline Modified fly ash sample & $\mathrm{K}_{\mathrm{a}}$ & $\Delta G_{a d s}^{o} \mathrm{Jmol}^{-1}$ \\
\hline SHFA-4 & 0.607 & 669.05 \\
SHFA-3 & 0.6462 & 1099.97 \\
SHFA-2 & 1.8001 & -1480.85 \\
SHFA-1 & 0.3334 & 55.267 \\
\hline
\end{tabular}

The results of this adsorption studies indicate that there were observed increases in the uptake of methylene blue due to increase dosage, the equilibrium data fitted well to the Freundlich isotherm which suggests multilayer adsorption processes ${ }^{20}$. SHFA-1 proved to have more affinity for methylene blue than the other forms of modified fly ash because of its high adsorption capacity $\left(\mathrm{K}_{\mathrm{F}}=77.04\right)$.

The negative value of Gibbs free energy of adsorption for SHFA-2 indicates that the sorption process in the case of methylene blue adsorption onto SHFA-2 was spontaneous 
while other were not, the kinetic data confirms the applicability of the pseudo-second-order kinetic model which also indicate a multilayer adsorption process. These results show that fly ash modified with $\mathrm{NaOH}$ could be an efficient adsorbent and the developed adsorption system could be useful for the removal of methylene blue from contaminated water.

\section{References}

1. Horsfall M Jr and Spiff AI, Principles of Environmental pollution, Toxicology and waste management, Oyoma research publications, Port Harcourt, Nigeria. 2013

2. Theivarasu C and Mylsamy S, J Chem., 2011, 8(SI), S363-S371; DOI: $10.1155 / 2011 / 714808$

3. Taha M E, J Environ Protection, 2011, 2, 817-827, DOI:10.4236/jep.2011.26093

4. Goswami A K, Kurlkarni S J, Dharmadhikari S K, Patil P E, Int J Sci Res Manage., 2014, 2(5), 842-845.

5. Khan T A, Ali I, Singh V V and Sharma S, J Environ Protection Sci., 2009, 3, 11-22.

6. Woolard C D, Petrus K M and Van der H, Water S.A, 2000, 26(4), 531-536

7. Malarvishi T S, Santhi T and Manonmani S, Res J Chem Sci., 2013, 3(2), 44-53.

8. Fungaro D A, Luca G C, Alessandro P S, Izdoro J C and Sueli B J, The Electronic J Chem, 2010, 2(3), 235-247.

9. Knaebel K S, Adsorption Research, Inc, Dublin, Ohio, 2014.

10. Vista M, World of coal ash (WOCA) conferences, Denver, CO, U. S. A. 2011. available: www.flyash.info

11. Isreal A A, Uduok U, Umoren S and Okon O, The Holist Appr Environ., 2013, 3(4), 209-222.

12. Bada S O and Potgeiter-Vermaak S, Leonardo Electronic J Pract Technol., 2008, 7(12), 37-48

13. Wankasi D, Adsorption a Guide to experimental Data Analysis, Ano Publication Company, Port Harcourt, Rivers State 2013.

14. Hameed B H and Foo K Y, Chem Engg J., 2010, 156(1), 2-10, DOI: $10.1016 /$ j.cej.2009.09.013

15. Pagga U and Braun D, Chemosphere, 1986, 15(4), 479-491; DOI:10.1016/00456535(86)90542-4

16. Sridevi V, Lakshmi C M V V and Yadla S V, Int J Innovative Res Sci, Engg technol., 2013, 2(11), 7022-7030.

17. Poota V J P, Mckay G and Healy J J, Water Res., 1976, 10(12), 1067-1670; DOI: 10.1016/0043-1354(76)90037-3

18. Song C, Wu S, Cheng M, Tao P, Shao M and Gao G, Sustainability, 2014, 6(1), 86-98; DOI:10.3390/su6010086

19. Hung P A and Hai N X, ARPN J Agr Biolog Sci., 2014, 9, 51-54.

20. Shabeig S, Baggeri N, Ghorbanians A, Hallajisani A and Poorkarimi S, World $J$ Modeling Simulation, 2013, 9(4), 243-254. 